\title{
Pengembangan Perusahaan Berbasis Nilai Islam pada Digital Startup
}

Indonesian Journal of Religion and Society, 2019, Vol. 01 (02), 115-125

(C) The Journal, 2019

DOI: $10.36256 /$ ijrs.v1i2.27

www.journal.lasigo.org/index.php/IJRS

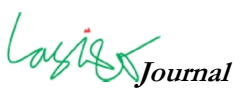

Article History

Received: May, $14^{\text {th }} 2019$

Revised: December, $8^{\text {th }} 2019$

Accepted: December, $14^{\text {th }} 2019$

\section{Safitri Maya Nastiti}

Jurusan Sosiologi, Universitas Indonesia, Depok, Jawa Barat, Indonesia

safitrimaya300@yahoo.com

\begin{abstract}
Lots of studies argue that company development is determined by innovation, adaptability, and institutional dynamism. This study aims to explain the development of islamic valuebased companies in digital startups, whereas the success factor of company is not only determined by innovation, adaptability, and institutional dynamism, but precisely caused by role of islamic values which was developed by the companies. Through qualitative approach, this results of study show that the islamic values which are the foundation of the company in carrying out to all operations of institution are Tauhid, Qonaah, competent, and moral. These islamic values at PT. Badr Interactive is built through the regulatory, normative, and cognitive cultural pillars. In general, islamic values play a role in four human resources, marketing, social responsibility, and corporate culture aspects. The influence of islamic values in these aspects produces an output of good quality product applications, good teamwork, strong employee resilience, employee spiritual needs, planned marketing strategies. These indicators are digital startup companies sources of success.
\end{abstract}

Keywords: islamic values, corporate development, startup digital, PT. Badr Interactive

\begin{abstract}
ABSTRAK
Banyak studi menunjukkan bahwa pengembangan perusahaan ditentukan oleh nilai inovasi, kemampuan beradaptasi, dan kedinamisan organisasi. Penelitian ini bertujuan untuk menjelaskan pengembangan perusahaan berbasis nilai islam pada digital startup, dimana faktor keberhasilan perusahaan tidak hanya ditentukan pada nilai inovasi, kemampuan beradaptasi, dan kedinamisan organisasi, akan ditentukan oleh peran penting nilai-nilai islam yang dibangun oleh perusahaan. Dengan menggunakan pendekatan kualitatif, hasil penelitian menunjukkan bahwa nilai islam yang menjadi landasan dalam menjalankan operasionalisasi perusahaan adalah nilai Tauhid, Qonaah, kompeten, dan akhlak. Pada PT. Badr Interactive, nilai-nilai tersebut terbangun melalui pilar regulatif, normatif, dan kognisi kultural perusahaan. Secara umum nilai-nilai islam berperan pada aspek human resource, marketing, social responsibility, dan corporate culture. Pengaruh nilai islam dalam keempat aspek ini kemudian menghasilkan output kualitas produk aplikasi yang bagus, teamwork yang baik, ketahanan karyawan yang kuat, kebutuhan rohani karyawan dan strategi marketing yang terencana. Semua aspek tersebut merupakan indikator keberhasilan perusahaan digital startup.
\end{abstract}

Kata Kunci: nilai islam; pengembangan perusahaan; digital startup; PT. Badr Interactive 


\section{Pendahuluan}

Pengguna internet di Indonesia mengalami perkembangan yang pesat. Asosiasi Penyelenggara Jasa Internet Indonesia (APJII) merilis hasil survei penetrasi pengguna internet di Indonesia sepanjang 2017 menyentuh angka 142,26 juta user atau sekitar 54,68 persen dari jumlah populasi penduduk Indonesia. Sebelumnya, di tahun 2016 sekitar 132,7 juta orang Indonesia menjadi pengguna internet. Dengan demikian, dalam kurun waktu satu tahun terjadi kenaikan pengguna internet sebesar hampir 10 juta. Penggunaan internet yang semakin banyak menyebabkan adanya kebutuhan teknologi digital yang semakin meningkat pada masyarakat Indonesia. Masyarakat Indonesia telah sampai pada apa yang dinamakan era digital dimana teknologi dianggap sebagai alat utama untuk mempermudah berbagai aktivitas. Lebih lanjut, teknologi digital telah menjadi gaya hidup baru di masyarakat, banyak pebisnis dan pemuda yang mendirikan perusahaan terkait dengan bidang digital, yakni dengan memunculkan perusahaan digital startup.

Startup merupakan perusahaan rintisan yang berbasis internet. Perusahaan startup mampu memenuhi kebutuhan digital masyarakat Indonesia, hal ini ditandai dengan 5 perusahaan startup yang menyandang gelar unicorn yang dirilis oleh lembaga riset AS, CBInsight yang artinya produk startup banyak diminati oleh masyarakat. Mudo (2015) mengungkapkan jumlah startup di Indonesia mencapai sekitar 1500-an dan semakin meningkat setiap tahunnya. Peningkatan ini terjadi karena melihat peluang pada masyarakat Indonesia yang setiap tahunnya mengalami peningkatan pengguna internet. Namun untuk dapat berkembang, perusahaan startup tidak semudah yang dibayangkan, dibutuhkan berbagai cara pengembangannya.

Salah satu faktor penting dalam pengembangan sebuah perusahaan adalah bagaimana membangun nilai organisasi. Penting untuk dicatat bahwa konsep nilai mencakup serangkaian makna dan dipahami dengan cara dan konteks yang berbeda, tidak semuanya akan secara langsung dikaitkan dengan moralitas. Nilai dapat mencakup "sebuah prinsip atau kepercayaan yang dianggap berharga atau diinginkan" (Paterno, 2001). Nilai adalah asas yang menggerakkan motivasi terhadap kerja dan menyokong pembentukan sikap positif yang akhirnya mempengaruhi tindakan dan pembuatan keputusan (Abdullah, Omar, Ab. Rahman \& Adham, 2013). Nilai dalam literatur perilaku organisasi, berkaitan dengan pengaruhnya terhadap hasil kerja (Chatman, 1991). Rokeach (1979), misalnya masih dikutip dalam sebagian besar penelitian saat ini tentang nilai-nilai kerja bersama dengan para peneliti baru lainnya seperti Palich, Hom dan Griffith (1990). Ada Korelasi yang signifikan telah dilaporkan antara nilai-nilai kerja dan efektivitas kinerja (Hackman \& Oldham, 1975).

Hingga bulan Maret 2019, dari sejumlah perusahaan startup yang ada hanya $10 \%$ yang berhasil survive di Indonesia. Pada perusahaan startup, nilai inovasi dan kreativitas merupakan nilai utama dalam penentuan keberhasilan organisasi. Inovasi menjadi suatu hal yang wajib, karena dalam pengembangan produk yang dilandasi dengan sistem berbasis teknologi, dan teknologi merupakan hal yang sangat dinamis. Hal yang menarik, di Indonesia saat ini berkembang beberapa perusahaan startup yang melandaskan nilai agama dalam aktifitas bisnisnya seperti Paytrend, Learning Quran dan Badr. Pengaruh nilai agama pada organisasi dapat dilihat misalnya pada penelitian Wahab (2012), yang menguji pengaruh nilai kerja islami terhadap hasil pekerjaan karyawan. Penelitian tersebut menunjukkan bahwa seorang pekerja yang beranggapan bahwa semakin tinggi praktik nilai-nilai kerja islami, semakin kuat pula pekerjaannya. Penelitian McLennan (2001) juga membuktikan bahwa seseorang yang bekerja dengan iman dapat menurunkan tingkat kerumitan dalam bekerja, tingkat stress, dan keseriusan dalam bekerja serta tingkat konsentrasi.

Implikasi dari pentingnya spiritualitas dalam organisasi adalah perlunya spiritualitas dikelola sebagai aset (Spiritual Capital) (Bahaudin, 2007; Liu, 2010; Zohar dan Marshall, 2004; Pudjiantoro dan Istadi, 2019). Namun baru sedikit penelitian yang meneliti tentang agama dan perusahaan digital. Perusahaan digital dan non-digital memiliki pola yang berbeda. Perusahaan digital mengutamakan komputerisasi dalam penciptaan kreasi dan solusi berbagai pemasalahan secara digital. Hal ini membuat inovasi dan kepekaan terhadap masalah-masalah di masyarakat diutamakan. Perusahaan digital setiap saat harus meneliti dan menghadirkan solusi masalah dalam bentuk digital.

Hal yang menarik dari fenomena agama dan perusahaan yang berbasis digital adalah banyaknya perusahaan yang mulai menerapkan nilai agama dalam operasional perusahaannya. Secara normatif, Habuburrahman (2019) memang berargumen bahwa islam mendorong manusia untuk tidak hanya beribadah, namun juga ddorong untuk memperhatikan kebutuhan dunia dengan berusaha untuk mencukupi kebutuhan, namun 
dalam studi ini bukan nilai demikian yang dimaksudkan. Nilai islam dalam studi ini lebih ke spirit sebeliknya, yaitu dakwah. Salah satu contoh perusahaan digital startup di Indonesia yang sukses dengan nilai islam adalah PT. Badr Interactive. Uniknya walaupun sebagai perusahaan digital, PT. Badr Interactive memiliki nilai-nilai islam dalam operasionalisasi perusahaannya. PT. Badr Interactive mempunyai visi membumikan islam dengan teknologi. Jadi, tujuan dari berbagai aktivitas dan berbagai produksi aplikasi dari PT. Badr Interactive sendiri adalah untuk membumikan islam. Nilai-nilai islam sebagai ideologi bersama dalam menjalankan perusahaan. Saat ini terdapat 5 aplikasi yang berjalan yang sedang dikembangkan oleh PT. Badr Interactive yang terdiri dari dari e-learning dan e-commerce, yaitu iGrow, yawmee, paytrend academy, NF juara, teman bisnis. PT. Badr Interactive memang konsisten menggabungkan teknologi dengan nilai-nilai islam, namun hal ini tidak membuat perusahaan mengalami kemunduran. Sebaliknya, PT. Badr Interactive berhasil terus berkembang dan mencapai banyak prestasi sebagai perusahaan digital startup terkemuka. Terbukti dari prestasi PT. Badr Interactive menjadi 20 besar perusahaan teknologi terbaik Indonesia versi majalah tekno preneur di tahun 2013.

Dengan membangun nilai islam pada perusahaannya, PT. Badr Interactive justru tetap mampu berkembang dengan baik. Nilai islam yang tertanam pada perusahaan merupakan hal yang unik, dimana sebelumnya nilai inovasi adalah yang paling utama dikembangkan pada perusahaan startup. Nilai-nilai islam, prinsip-prinsip islam merupakan landasan dalam operasionalisasi PT. Badr Interactive. Bagi pegawai, nilai-nilai islam juga menjadi acuan dalam melaksanakan pekerjaannya. Tulisan ini membahasa peran nilai islam dalam pengembangan perusahaan digital startup PT. Badr Interactive. Selain iyu, tulisan ini juga memabahas proses pengembangan perusahaan digital startup berbasis nilai islam PT. Badr Interactive dengan menggunakan kerangka institusi.

\section{Kerangka Teori}

\subsection{Organisasi dalam Pendekatan New Institutionalism}

Organisasi berhubungan dengan teori instiusi. Selanjutnya lahirlah teori neo institusi dalam pertemuan antara teori institusi dengan organisasi. Interaksi kedua teori ini menurut Scott (1995) terjadi sejak tahun 1970-an, yang ditandai oleh munculnya kajian mengenai bentuk-bentuk organisasi dan ranah organisasi. Diawali dari pemikiran Weber dan teori birokrasinya, kemudian diikuti Parsons dengan kelembagaan kulturalnya. Selanjutnya pada Herbert Simmon yang bekerjasama dengan James G. March yang mempelajari ciri rasionalitas pada organisasi, Selznick yang mempelajari teori kelembagaan terhadap organisasi (Scott, 2004), serta Victor Nee dalam konteks analisa kelembagaan (institutional analysis) yang mempelajari hubungan antara proses formal dan informal pada lingkungan kelembagaan (institutional settings).

Studi-studi pada new institusionalism biasanya erat hubungannnya dengan pengaruh institusi perilaku manusia melalui aturan (rules), norma (norms), dan kultural-kognitif (cultural-cognitive) yang dibangun dan di persepsi oleh aktor. DiMaggio dan Powell (1991) menjabarkan kelembagaan baru dengan menolak model aktor rasional dari pemikir klasik. Sedangkan menurut Scott (1995), akar teoritis kelembagaan baru berasal dari teori kognitif (sosiologi pengetahuan), teori kultural, fenomenologi dan etnometodologi. Menurutnya ada tiga pilar yang membangun institusi, yaitu pilar regulatif, normatif dan kultural-kognitif.

Menurut Scott (1995) institusi dibangun dari elemen-elemen regulatif, normatif, dan budaya-kognitif yang semuanya dikaitkan dengan kegiatan-kegiatan dan sumber daya, yang memberikan stabilitas dalam kehidupan sosial. Scara rinci, Scott (1995) menjelaskan tiga pilar tersebut:

1) Pilar Regulatif merupakan peraturan yang ada. Peraturan berupa kekuatan, kebijakan-kebijakan, dan juga terdapat sanksi yang ditetapkan bagi yang melanggarnya. Dengan aturan regulasi lembaga bisa memberi lisensi, kekuasaan khusus, dan manfaat bagi lembaga itu sendiri.

2) Pilar Normatif mupakan kumpulan norma norma yang digunakan dalam suatu lembaga, dimana norma tersebut merupakan prinsip dasar bagi pelaksanaan kebijakan-kebijakan dalam lembaga. Konsepsi normatif dalam lembaga mempengaruhi stabilitas sosial dan norma-norma yang baik bagi masyarakat. Pilar normatif tentunya berkaitan dengan norma, yang menurut para sosiolog seperti Durkheim, Parsons, Sumner dan Cooley, Selznick, Soekanto, serta Uphof merupakan penentu utama pada perilaku individu dalam masyarakat. Lebih 
lengkapnya Parson menyebutkan bahwa "sistem norma mengatur bagaimana relasi antar individu semestinya" (Scott, 2004). Norma merupakan komponen pokok dalam institusi karena memberi pengetahuan tentang tujuan, dan bagaimana cara mencapai tujuan. Norma akan menghasilkan presepsi, bersifat evalualtif, dan melahirkan tanggung jawab dalam kehidupan aktor di masyarakat.

3) Pilar Kognitif budaya yaitu berbagai kebiasaan yang sudah menjadi budaya yang ada dalam lembaga. Kognitif dalam makna budaya merupakan kumpulan dari berbagai idealisme, keyakinan pengikat maupun tekanan institusi. Kognitif budaya memiliki sifat yang lebih flexsible dibangding kedua pilar di atas. Lebih lanjut Scott mencoba menerangkan tiga pilar institusi dalam tabel berikut:

Tabel 1. Tiga Pilar Institusi

\begin{tabular}{|c|c|c|c|}
\hline \multirow{2}{*}{ Aspek Pembeda } & \multicolumn{3}{|c|}{ PILAR } \\
\hline & Pilar Regulatif & Pilar Normatif & Pilar Kultural-Kognitif \\
\hline Dasar kepatuhan & Kelayakan & Kewajiban sosial & $\begin{array}{l}\text { Kebenaran/kesepahaman } \\
\text { bersama }\end{array}$ \\
\hline Aturan & Aturan regulatif & Ekspektasi mengikat & Skema Konstitutif \\
\hline Mekanisme & Pemaksaan & Normatif & Meniru-niru \\
\hline Logika & Instrumentalitas & Kepatutan & Ortodoksi \\
\hline Indikasi & $\begin{array}{l}\text { Aturan hukum } \\
\text { Sanksi }\end{array}$ & Sertifikasi akreditasi & $\begin{array}{l}\text { Keyakinan bersama } \\
\text { Tindakan logis yang diakui } \\
\text { bersama }\end{array}$ \\
\hline Basis legitimasi & $\begin{array}{l}\text { Disanksi secara } \\
\text { hukum }\end{array}$ & $\begin{array}{l}\text { Diarahkan secara } \\
\text { moral }\end{array}$ & $\begin{array}{l}\text { Mudah dipahami } \\
\text { Dapat diketahui } \\
\text { Didukung oleh budaya }\end{array}$ \\
\hline
\end{tabular}

Sumber: Scott (1995)

Selanjutnya kerangka analisis tiga pilar ini oleh Scott dikaitkan dengan beberapa elemen lainnya yaitu kultural (sistem simbolis), struktur sosial (sistem relasi), dan routines (rutinitas). Elemen-elemen ini dapat digunakan untuk memahami konsekuensikonsekuensi dalam operasionalisasi satu lembaga termasuk di dalamnya konflik dan dinamika struktur.

Tabel 2. Kerangka Pilar dan Elemen Institusi

\begin{tabular}{|c|c|c|c|}
\hline \multirow{2}{*}{ Carriers } & \multicolumn{3}{|c|}{ Pilar } \\
\hline & Regulatif & Normatif & Kultural-Kognitif \\
\hline Sistem simbolis & Aturan dan hukum & Nilai dan ekspektasi & $\begin{array}{l}\text { Kategori, tipifikasi dan } \\
\text { skema }\end{array}$ \\
\hline Sistem Relasi & $\begin{array}{l}\text { Pemerintah dan sistem } \\
\text { kekuasaan }\end{array}$ & $\begin{array}{l}\text { Rezim dan sistem } \\
\text { otoritas }\end{array}$ & $\begin{array}{l}\text { Identitas isomorfisme } \\
\text { struktural }\end{array}$ \\
\hline Rutinitas & $\begin{array}{l}\text { Protokol, standar, } \\
\text { operasi dan prosedur }\end{array}$ & $\begin{array}{l}\text { Pekerjaan, peran dan } \\
\text { kepatuhan pada tugas }\end{array}$ & Naskah \\
\hline
\end{tabular}

Sumber: Scott (1995)

\subsection{Nilai Islam PT. Badr Interactive dalam Kerangka new Institusi}

Penelitian Alfalih (2016) di Arab Saudi, islam memiliki kekuatan yang berdampak pada tempat kerja di negara-negara islam, yang sebagian besar dilakukan melalui tekanan institusional, peraturan dan normatif, yang mencerminkan budaya dan sistem hukum dirancang sesuai dengan hukum islam. Sementara dalam PT. Badr Interactive dari segi regulasi sebagai perusahaan digital startup, menjalankan operasionalisasi berdasarkan AlQuran dan Hadist. Pada sistem simbolik akan dilihat peran Al-Quran dan Hadis sebagai regulasi yang menjalankan perusahaan PT. Badr Interactive. Pada sistem relasi akan dilihat bagaimana pengaruh Al-Quran dan hadis pada perilaku karyawan. Pada elemen rutinitas regulatif akan melihat pelaksanaan mekanisme operasionalisasi perusahaan yang telah ditetapkan. Sementara itu pada pilar normatif dari elemen sistem simbolik, penelitian ini ingin mengkaji norma-norma dalam perusahaan seperti etika market PT. Badr Interactive dalam menjalankan perusahaan, terutama aturan dalam pengembangan produk aplikasi. Kemudian sistem relasi normatif lebih mengacu pada sistem otoritas yang ada. Sedangkan elemen rutinitas normatif digunakan untuk melihat kepatuhan karyawan terhadap aturan 
perusahaan. Pilar berikutnya yaitu kultural-kognitif, dimana pada sistem simbolik elemen simbolik digunakan untuk melihat skema staffing pada perusahaan. Pada sistem relasi akan menjelaskan hubungan nilai islam dengan perilaku karyawan. Terakhir rutinitas kultural-kognitif dalam bentuk seberapa dalam nilai islam yang tertanam pada karyawan seperti bekerja adalah dakwah, ibadah, jihad.

Bagan 1. Skema Nilai pada PT. Badr Interactive

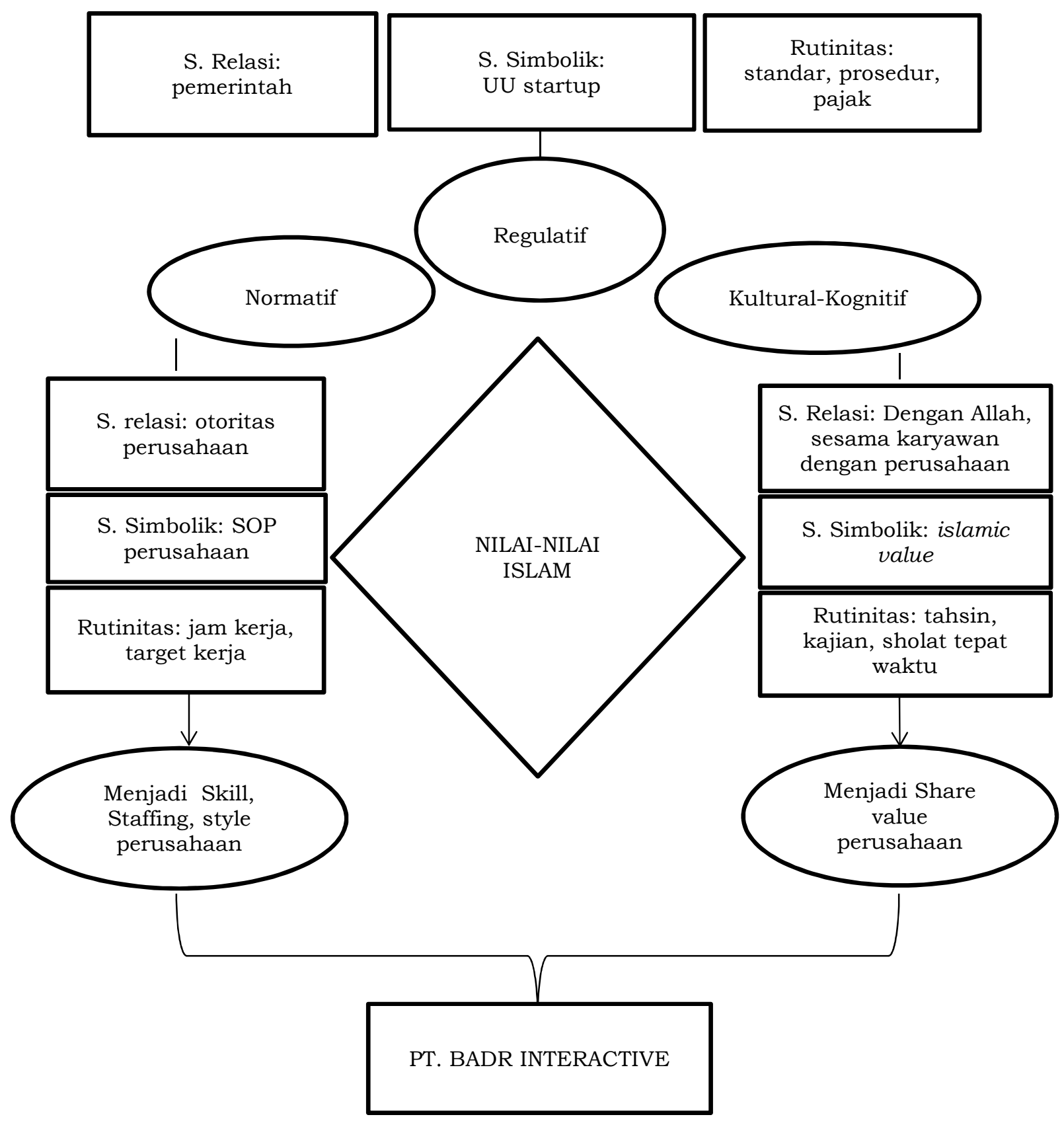

\section{Metode Penelitian}

Penelitian ini menggunakan pendekatan kualitatif yang merupakan pendekatan holistik yang melibatkan penemuan (Creswell, 2002). Dengan menggunakan pendekatan kualitatif melalui studi kasus, data diperoleh melalui wawancara mendalam dengan para founder, pegawai perusahaan, pengguna Aplikasi. Selain wawancara, juga dilakukan observasi. Kedua teknik 
pengumpulan data dilakukan untuk menjelaskan peran nilai-nilai islam dalam perusahaan PT. Badr Interactive. Yakni bagaimana peran nilai-nilai islam tersebut terhadap proses pengembangan perusahaan tersebut. Berbagai nilai bersama dari sebuah perusahaan memiliki peran mendasar dalam operasionalisasi sebuah organisasi dalam perusahaan. Dalam penelitian ini, peneliti berusaha sedetail mungkin menggambarkan nilai-nilai islam yang dibangun oleh perusahaan dan pada akhirnya dimiliki sebagai nilai bersama di perusahaan PT. Badr Interactive sendiri. Dalam rangka mencapai hasil yang komprehensif maka penulis melakukan beberapa tahapan.

Penulis menggali awal mula berdirinya perusahaan, kemudian penulis mencari biografi founder dari perusahaan, dan melihat bagaimana latar belakang dan biografi fouder perusahaan. Selanjutnya penulis menggali nilai-nilai filosofis yang diinternalisasikan dari PT. Badr Interactive. Penulis juga melihat perilaku organisasi para karyawan PT. Badr Interactive, apakah menunjukkan nilai-nilai islam di dalamnya. Peneliti mencari tahu bagaimana perkembangan perusahaan dari mulai terbentuknya sampai saat penelitian. Peneliti menjabarkan aspek yang membuat PT. Badr Interactive bisa berkembang serta raihan prestasi yang diraih oleh perusahaan PT. Badr Interactive. Selanjutnya peneliti mencocokkan nilai dalam perusahaan dan keberhasilan organisasi yang saling berhubungan. Dan yang terakhir peneliti mencoba menambahkan temuan-temuan yang ada di lapangan untuk memperkaya teori yang sudah ada.

Peneliti melihat hal ini cukup menarik karena kebanyakan perusahaan yang berkembang pesat adalah perusahaan dengan memakai manajemen modern dengan ideologi kapitalis dengan menekankan nilai-nilai inovatif dan kreatif, namun dengan nilai agama islam PT. Badr Interactive mampu bertahan dalam dunia startup terbukti PT. Badr Interactive menjadi perusahaan Indonesia pertama yang masuk dalam program inkubasi 500 Startups accelerator. Baik dalam prinsip maupun aktivitas, nilai islam menjadi dasar operasional perusahaan. Hal ini membuat pertanyaan bagi peneliti bagaimana peran nilai islam dalam pengembangan organisasi pada PT. Badr Interactive. Dalam proses penelitian, peneliti memutuskan hanya terfokus pada studi kasus pada PT. Badr Interactive.

\section{Profil PT. Badr Interactive}

PT. Badr Interactive merupakan perusahaan startup di Indonesia yang didirikan oleh Andreas Senjaya pada tahun 2011. Alamat perusahaan berada di Jl. Pesona Depok Estate II, No.2, Depok, Pancoran Mas, Kota Depok, Jawa Barat 16431. Pendirian perusahaan diawali dari rasa penasaran founder Andreas Senjaya atau lebih sering di panggil "Bang Jay" tentang dunia startup dan hasil eksperimennya untuk membuat startup. Terlebih Bang Jay merupakan seorang mahasiswa ilmu komputer di universitas Indonesia. Bang Jay bersama 2 kawannya Mohammad Sani dan Yuwono Mujahidin akhirnya mulai merintis perusahaan Badr Interactive pada akhir masa kuliah.

Nama perusahaan Badr Interactive diambil dari nama peperangan yang terjadi di zaman Rasulullah berdakwah, yaitu perang badar. Kisah perang badar sendiri adalah kisah yang paling membekas dalam perjalanan umat islam dimana saat itu islam hanya memiliki kekuatan sedikit tetapi akhirnya dalam peperangan tersebut umat islam mendapat kemenangan. Jadi dari hikmah yang diambil dari terjadinya perang badar adalah dimana kemenangan tetap jatuh pada umat islam walaupun jumlah pasukan umat islam saat itu sangat sedikit dan kalah jauh dari musuh.

Dari kisah tersebut diharapkan keberhasilan juga dapat terjadi dalam perusahaan dimana walaupun memiliki jumlah yang kecil namun dapat mengorganisasi kekuatan yang besar sehingga tercapailah keberhasilan tersebut, juga filosofi bahwa ukuran bukan merupakan tolak ukur keberhasilan tetapi ketakwaan kepada Allah adalah sumber dari keberhasilan yang akan diraih. Jika dilihat dari pemberian nama perusahaan, terlihat bahwa nilai keislaman adalah platform utama dari perusahaan. Perusahaan PT. Badr Interactive dibangun dengan nilai-nilai keislaman.

PT. Badr Interactive memiliki karyawan sebanyak 62 orang. Memiliki konsep bahwa kantor adalah rumah kedua menjadikan pekerjaan dibuat lebih santai tetapi efektif. Untuk struktur organisasinya, PT. Badr Interactive dibagi menjadi 2 sub bagian perusahaan yaitu Tim Proyek dan Tim Produk. Tim Proyek pada PT. Badr Interactive menangani berbagai proyek kerjasama dengan berbagai perusahaan lain, sementara untuk Tim Produk lebih fokus menangani berbagai produk aplikasi yang dikembangkan oleh perusahaan PT. Badr Interactive. 
Tim Proyek mengerjakan aplikasi yang tidak hanya tentang islam, tetapi dari siapapun permintaan proyek tersebut bisa diterima, namun tetap dengan syarat-syarat yang harus dipenuhi. Syarat-syarat suatu proyek yang paling utama adalah proyek tidak boleh bertentangan dengan nilai islam berapapun keuntungan yang ditawarkan. Proyek-proyek yang diambil oleh tim harus sesuai dengan syariat islam yang dipegang perusahaan. Misalnya tidak mengambil proyek dari bank konvensional karena mereka beranggapan akan ikut berkontribusi dalam riba dan riba adalah salah satu yang bertentangan dengan nilai islam, kemudian aplikasi-aplikasi ramalan nasib mereka tidak mau menerima karena termasuk perbuatan yang mengandung syirik kepada Allah.

Sementara pada Tim produk, menyediakan layanan inkubasi startup. Produk tidak spesifikasi khusus dengan konten islam tetapi lebih pada nilai-nilai islam apa yang bisa dibangkitkan pada produk-produk tersebut. Dan ada juga produk-produk untuk masyarakat umum yang bernilai sosial dimana dasar pengerjaannya adalah "memberi manfaat" kepada manusia. Terdapat beberapa aplikasi yang sedang dikembangkan oleh PT. Badr Interactive yaitu, Complete Quran, Igrow, Paytrend Academy, NF juara dan Yawmee

\section{Nilai Islam di PT. Badr Interactive 5.1. Tauhid}

Nilai Tauhid merupakan fondasi bagi para karyawan dalam melaksanakan pekerjaannya dimana mereka bekerja untuk beribadah kepada Allah. Tauhid berarti rasa percaya pada keesaan Allah. Tauhid memiliki konsekuensi yaitu dalam setiap langkah kehidupan haruslah menaati segala perintah Allah dan menjauhi larangan Allah. Konsekuensi ini merupakan bentuk komitmen atau sebagai penghambaan dirinya di hadapan Tuhan melalui tindakan yang dilakukan. Nilai Tauhid ini yang mendorong beberapa perilaku karyawan dalam perusahaan yaitu: Pertama, memastikan bahwa kerja yang dilakukan berada dalam koridor nilai-nilai peribadatan yang dikehendaki Tuhan, seperti perintah wajib untuk mencari nafkah, menghindari praktek riba dan melarang segala penciptaan produk yang bertentangan dengan islam. Kedua, menciptakan produk yang dinilai bisa membangkitkan nilai-nilai islam

Bekerja sebagai bentuk ibadah merupakan implementasi dari nilai tauhid yang dipegang oleh para karyawan. Nilai tauhid tersebut adalah pengakuan pada Allah sebagai zat yang disembah dan diibadahi. Maka dari itu, niat dalam bekerja adalah untuk beribadah kepada Allah sebagai bentuk nilai tauhid yang mereka tanamkan. Konsep kepatuhan syariah harus lebih unggul dari konsep lain. Muslim wajib mengimplementasikan semua elemen sebagai tindakan ibadah, yang bertujuan untuk mendapatkan rida'atau berkah dari Allah SWT dalam usaha hidup mereka (Ahmad, 2016). Islam lebih merupakan "jalan hidup" lebih dari agama belaka, islam mengajarkan bagaimana seorang percaya harus mewajibkan komitmen untuk imannya (Bilal, Ayesha dan Zareen, 2010). Komitmen keimanan yang mendasar adalah tauhid.

\subsection{Qanaah}

Qanaah bermakna merasa puas dengan apa yang diterima dan rela atas bagianya. Sedangkan secara istilah qanaah merupakan perilaku menerima rezeki apa adanya dan menganggapnya sebagai kekayaan yang membuat mereka terjaga statusnya dari memintaminta kepada orang lain. Sifat qonaah adalah bentuk dari kepuasan diri dalam menerima apa saja yang telah Allah berikan. Berkaitan dengan konsep rizki, bagaimanapun dalam islam harus ada kendali terhadap ambisi, tidak boleh selalu merasa kurang dalam konsep rizki yang sudah ditetapkan Allah. Yang dipegang adalah tidak mudah putus asa jika penghasilan yang didapat hanyalah sedikit karena pada dasarnya di Tim Proyek penghasilan tidak menentu tergantung bagaimana proyeknya. Qonaah juga sebagai nilai yang akan mencegah kerakusan terhadap harta atau penghasilan yang akan diterima perusahaan. Dengan memiliki nilai qonaah profit bukanlah tujuan utama dari pekerjaan yang telah dilakukan. qonaah bukan berarti pasrah dan tidak berusaha, namun lebih kepada ketika usaha dan doa sudah dalam level maksimal berapapun rizki yang didapat akan diterima dengan rasa puas serta mensyukurinya.

\subsection{Amanah}

Maksud amanah di sini adalah tanggung jawab para karyawan mengerjakan setiap proyek sesuai akad atau kesepakatan dengan para mitra kerja. Karyawan menjadi sangat menjaga perjanjian yang telah disepakati antara tim dan perusahaan yang memberi pekerjaan. Nilai 
amanah ini membuat pekerjaan selalu diusahakan sesuai dengan akadnya seperti deadline pengerjaan, konsep dan lain-lain sesuai dengan kesepakatan antara perusahaan dengan mitra perusahaan.

\subsection{Kompeten}

Nilai kompeten adalah kemampuan untuk menyelesaikan pekerjaan sesuai dengan permintaan para mitra. Setiap karyawan dituntut memiliki nilai kompeten karna dalam islam sendiri menyuruh manusia untuk handal dalam mengerjakan sesuatu. Seperti termaktub dalam Surat Alqashash ayat 26 - 28. Nilai ini berkaitan dengan profesionalisme seorang muslim dalam melaksanakan pekerjaanya.

\subsection{Akhlaq}

Akhlak ini adalah perilaku yang ditunjukkan para karyawan perusahaan dalam bermitra atau bermuamalah. Akhlak bisa disebut sebagai moral. Berbagai moral, spiritual dan fisik yang tidak hanya didorong oleh tujuan duniawi tetapi juga oleh imbalan di akhirat (Branine \& pollard, 2010). Tujuan dari moral yang dimiliki ini adalah dakwah. Perilaku yang harus di miliki adalah baik, sopan dan ramah. Dalam nilai akhlak ini tujuan utama sebenarnya adalah ingin menunjukkan kepada perusahaan lain bahwa sebagai startup yang islami para karyawan PT. Badr Interactive memegang prinsip akhlak yang mulia kepada para mitra kerja. Karyawan PT. Badr Interactive ingin mendakwahkan bahwa dengan islam, berusaha adalah berakhlak termasuk saat bermuamalah. Intinya dengan akhlak mulia, PT. Badr Interactive ingin berdakwah. Membangun akhlak yang mulia kepada para karyawan dan mempraktekkannya pada para mitra kerja. Hal ini dapat dikatakan sebagai dakwah terselubung melalui citra diri para karyawan. Para karyawan PT. Badr Interactive diwajibkan memiliki sifat yang baik dan dapat memperlakukan perusahaan mitra dengan baik dalam bekerjasama.

\section{Peran Nilai Islam dalam Pengembangan Perusahaan}

Nilai-nilai islam sebagaimana diuraikan di atas memiliki peran pada empat aspek penting perusahaan, yaitu human resource management, marketing, sosial responsibility dan Budaya perusahaan. Keempat element ini adalah sebagai penentu atau indikator keberhasilan perusahaan.

\subsection{Human Resource Management}

Faktor kunci keberhasilan inisiatif digital di masa depan adalah sumber daya manusia yang terampil (Ahlemann, 2016). Dalam pengelolaan sumber daya manusia, tujuan pertama dari perusahaan adalah menjadikan karyawan lebih baik di sisi agama dibanding sebelumnya. Pembentukan budaya islami di dalam perusahaan dilakukan melalui pengajian, tahsin yang rutin, serta sholat tepat waktu. Jadi ketika bekerja dan sudah adzan semua karyawan yang laki-laki akan berangkat ke masjid untuk melaksanakan sholat. Jadi hak Allah akan tetap diutamakan. Sementara itu dalam kajian yang dibahas tentang ilmu-ilmu agama melalui berbagai sumber bacaan seperti kitab minhajul muslim dan sebagainya. Sedangkan untuk tahsin adalah opsional, dalam artian jika ada yang ingin ikut diperbolehkan dan jika tidak berminat untuk mengikuti juga dipaksakan untuk mengikuti. Budaya islami perusahaan diciptakan dan dibentuk supaya tidak ada pertentangan antara berbagai kewajiban sebagai umat Muslim dengan pekerjaan. Selain itu, juga dilakukan kegiatan meet-up yang sifatnya mengingat lagi target perusahaan. CEO sering mengingatkan tentang nilai-nilai islam melalui video atau secara lisan. Niat ikhlas tentang ibadah dan makna tentang rizki. Konsep rizki selalu diingatkan Secara umum amanah, ibadah, kebermanfaatn pada masyarakat. Dalam muamalah jika ada request tentang hal-hal yang bertolak belakang dengan nilai islam seperti fitur aplikasi ramalan, maka akan ditolak.

Melalui berbabagai kegiatan keagamaan, perubahan yang terjadi pada para karyawan adalah sholat lebih terjaga. Motivasi dan pengingat. Menunjukkan jalan kebaikan. Pengingat harus hati hati. Dasar-dasar keislaman sudah punya. Kadang konsultasi ke ustadz untuk mengambil keputusan. Penolakan dilakukan terhadap industri rokok, bank konvesional, halhak yang bersifat fundamental, dipegang bersama. Fundamental secara tidak langsung sudah disepakati bersama. Hal-hal fundamental seperti perusahaan ribawi disepakati oleh semua karyawan untuk tidak diperbolehkan. 
Nilai Ukhuwah adalah nilai dasar dalam menjalin relasi teamwork perusahaan. Memperlakukan partner kerja sebagai saudara adalah aspek yang sangat penting, walaupun terkesan sederhana tetapi bagi sebuah perusahaan yang masih berkembang, persaudaran adalah modal yang penting untuk saling bekerjasama dan melakukan penguatan. Apalagi di masa masa awal dimana perusahaan dalam masa berjuang rasa persaudaraan dan kekeluargaan akan membuat bergerak menuju kondisi yang ideal.

\subsection{Marketing}

Frame of mind dalam menjalankan marketing di PT. Badr Interactive adalah dengan akidah berdasarkan syariah. Ide kreatif dan inovatif tidak boleh dibatasi tetapi saat PT. Badr Interactive membangun perusahaan dengan nilai islam, gagasan itu tidak semata-mata bebas nilai. Gagasan harus dibangun di dalam landasan yang benar yaitu nilai islam. Gagasan yang bertentangan dengan islam tidak boleh dipakai. Aspek syariah bukan hanya klaim, akan tetapi diimplementasikan secara keseluruhan. Akidahnya adalah islam dan operasionalnya adalah secara syariah. Masalah akad, interaksi tidak sebebas seperti perusahaan yang lain. PT. Badr Interactive tidak menerima proyek dari produk-produk yang mengandung unsur riba dan bertentangan dengan nilai islam. PT. Badr Interactive juga tidak menerima investor yang memiliki nilai yang bertentangan dengan nilai islam seperti riba. Dalam bekerjasama, PT. Badr Interactive juga memiliki tujuan untuk mendakwahkan berbagai nilai islam kepada partner atau mitra kerja. Sikap qonaah yang diperlihatkan perusahaan yaitu bagaimana mereka tidak ambisus dalam mengejar keuntungan jika keuntungan tersebut melanggar syariat. Maka cara marketing yang benar dan sesuai syariat dipilih oleh PT. Badr Interactive.

\subsection{Social Responsibility}

Tanggung jawab sosial dalam perusahaan islami diindikasikan lebih rendah dari perusahaan biasa. Penelitian Durrani (2016) menyatakan bahwa bank konvensional lebih banyak berkontribusi dalam tanggung jawab sosial dibandingkan dengan bank syariah di Pakistan. Sementara tanggung jawab sosial PT. Badr Interactive masih melingkupi pada tanggung jawab sosial yang bersifat islami, juga pada karyawan yang berkecimpung di dalamnya. Tanggung jawab tersebut daktualisasikan antara lain melalui rencana program asuransi syariah bagi karyawan dan keluarga karyawan, komitmen kompensasi untuk sedekah dari hasil usaha, pembangunan masjid, rumah tahfiz, donasi bagi daerah yang terkena bencana alam, waqaf dan lain sebagainya. Membangun kemitraan positif baik secara horisontal maupun vertikal. Tanggung jawab sosial perusahaan serta karyawan di dalamnya bisa diwujudkan dalam bentuk kemitraan vertikal yang baik, yaitu antar perusahaan dengan tujuan keberlangsungan perusahaan itu sendiri. Karena pada hakikatnya, berdirinya satu perusahaan dengan perusahaan lain adalah untuk bekerja sama demi kemakmuran dan kesejahteraan bangsanya. Sedang kemitraan secara horisontal dapat diwujudkan dengan kepedulian perusahaan terhadap masyarakat sekitar perusahaan serta saling melengkapi dengan tujuan silaturahmi.

\subsection{Corporate Culture}

Corporat culture adalah situasi kerja dimana budaya dijadikan alat untuk membuat situasi kerja kondusif. Misalnya salah satu culture google adalah transparansi dan kolaborasi. Culture hanyalah tools melahirkan produk yang bisa melahirkan perbaikan atau mempercepat perbaikan, melempar ke pasar, cara untuk mempermudah. Culture harus original, tidak boleh bertentangan dengan nilai-nilai perusahaan. Budaya relijius yang terlihat pada perusahaan PT. Badr Interactive ini seperti sholat tepat waktu dimana karyawan meninggalkan pekerjaaanya saat azan, tidak bercampur antara laki-laki dan perempuan dalam interaksi. Terdapat kajian rutin yang dilaksanakan untuk meningkatkan ilmu agama. Ada juga program tahsin yang dilakukan untuk meningkatkan bacaan Al-Quran. Programprogram yang dirancang membentuk budaya yang relijius untuk para karyawan dan hal ini membuat situasi kerja yang kondusif karena dapat memenuhi kebutuhan rohani karyawan.

\section{Kesimpulan}

Berdasarkan hasil temuan lapangan, dapat disimpulkan bahwa nilai islam yang ada pada peusahaan PT. Badr Interactive adalah nilai tauhid, qonaah, kompeten, amanah dan akhlak. Nilai tersebut memiliki banyak peran dalam pengembangan perusahaan digital 
startup. Salah satunya adalah motivasi dalam beribadah dan berdakwah melalui perusahaan. Hasil ini menunjukkan bahwa nilai islam bisa sejalan dengan profitabilitas dan juga bisa sejalan dengan inovasi. Tidak ada resistensi nilai islam di dalam karyawan karena mereka telah terseleksi sejak awal dengan nilai islam yang diterapkan. Nilai-nilai islam terealisasi dalam perusahaan melalui relasi antara nilai islam pada tiga pilar teori neo institusionalism, yaitu pilar regulatif, normatif dan kognitif. Nilai-nilai islam dalam PT. Badr Interactive terbangun melalui pilar regulatif, normatif, dan kultural kognitif perusahaan.

Secara umum nilai-nilai islam berperan pada aspek human resource, marketing, social responsibility, dan budaya perusahaan. Pengaruh nilai islam dalam keempat aspek ini kemudian menghasilkan output kualitas produk aplikasi yang bagus, teamwork yang baik, ketahanan karyawan yang kuat, kebutuhan rohani karyawan yang terpenuhi, strategi marketing yang terencana, dimana kesemua aspek tersebut merupakan indikator keberhasilan perusahaan digital startup. Value yang dibangun para pengusaha startup biasanya lebih menekankan pada kreativitas, keuletan dan toleransi yang tinggi terhadap ketidakpastian. Namun pada PT. Badr Interactive ini nilai islam adalah nilai yang dikembangkan dalam operasionalisasi perusahaan. Nilai islam utama di perusahaan adalah dakwah melalui digital, dimana dakwah adalah bagian dari nilai islam yang diambil oleh PT. Badr Interactive sebagai kewajiban bagi setiap seorang muslim. Dakwah menjadi pendorong nilai-nilai yang memang tidak bisa dipungkiri dibutuhkan oleh startup seperti inovatif, kreativitas, mampu mengambil resiko, ulet yang kesemua itu dapat dicapai dan dihadapi oleh perusahaan. Nilai dakwah sendiri menciptakan keteguhan hati karyawan karena niat yang mereka bangun dari awal adalah tujuannya mencari ridho Allah semata. Nilai islam memegang peranan penting pada perjalanan PT. Badr ini karena menciptakan kondisi survive yang tinggi dengan segala resiko kegaagalan startup.

Menyangkut banyaknya nilai islam yang dibangun di dalam PT. Badr Interactive peneliti menemukan nilai dakwah sebagai landasan dan nilai pokok dalam melaksanakan segala operasionalisasi perusahaan. Adapun nilai-nilai lainnya yang mencakup kompeten, akhlak, amanah, dan qonaah adalah nilai pendukung. Nilai-nilai islam yang dibangun dalam perusahaan berperan penting dalam pengembangan perusahaan. Secara kelembagaan PT. Badr Interactive diatur oleh pemerintah dengan UU startup, yang kedua aspek normatif norma dan nilai yang mengatur disepakati bersumber dari Al- Quran dan Hadist. Dan secara kognitif kolektif PT. Badr Interactive memiliki budaya organisasi yang religius.

\section{Acknowledgment}

Penulis mengucapkan terima kasih kepada Bapak Dr. Ricardi S. Adnan, dosen sosiologi Universitas Indonesia atas saran dan bimbingannya dalam proses penulisan artikel ilmiah ini.

\section{Funding}

Penelitian ini dilakukan dengan dana pribadi dan tidak menerima hibah dan atau dana penelitian dari lembaga manapun.

\section{Conflicts of Interest}

Penulis menyatakan tidak ada konflik kepentingan dalam penelitian ini.

\section{Daftar Pustaka}

Abdullah, N. A., Omar, F., Ab. Rahman, N. M. N, \& Adham, K. A. (2013). Conceptualizing work and organizational values from the Islamic perspective. Jurnal Pengurusan, 39(2013), 119-128.

Ahlemann, F. (2016). How digital transformation shapes corporate IT: Ten theses about the IT organization of the future. Proceedings of the 2016 Federated Conference on Computer Science and Information Systems, 8, https://doi.org/10.15439/2016f597

Ahmad, N., Shafique, M. N., \& Ahmad, H. (2016). Islamic Principles and Values in Modern Organizations. Nigerian Chapter of Arabian Journal of Business and Management Review, 3(10), 1-8. https://doi.org/10.12816/0017681

Alfalih, A. (2016). Religion, culture and management: a comparative study of the impact of Islam and Saudi culture on HRM practices of indigenous and foreign owned and managed corporations in Saudi Arabia. Retrieved from 
http://hdl.handle.net/2436/618494

Asosiasi Penyelenggara Jasa Internet Indonesia [APJII]. (2014). Profil Pengguna Internet Indonesia. Jakarta: Asosiasi Penyelenggara Jasa Internet Indonesia.

Bahaudin, T, 2007. Brainware Leadership Mastery - Kepemimpinan Abad Otak dan Milenium Pikiran. Jakarta: PT. Elex Media Komputindo

Bilal, K., Ayesha, F., \& Zareen, H. (2010). Human Resource Management: An Islamic Perspective. Asia-Pacific Journal of Business Administration, 2(1), 17-34. https://doi.org/http://dx.doi.org/10.1108/MRR-09-2015-0216

Branine, M., \& Pollard, D. (2010). Human resource management with islamic management principles. Personnel Review, 39(6), 712-727. https://doi.org/10.1108/00483481011075576

Chatman, J. A. (1991). Matching People and Organizations: Selection and Socialization in Public Accounting Firms. Administrative Science Quarterly, 36,459-484

Creswell. (2002). Qualitative, quantitative, and mixt method approach (second edi). london.

Dimaggio, P. J. and W.W. Powell. (1991). The New Institutionalism In Organizational Analysis. Chicago: University of Chicago Press.

Durrani, B. (2016). Islamic Concept and Contemporary Corporate Social Responsibility: Comparative Study between Islamic Banks and Conventional Banks in Pakistan. Journal of Management Sciences, 10(2), 317-332. Retrieved from http://www.qurtuba.edu.pk/jms/default_files/JMS/10_2/JMS_July_December2016_3 17-332.pdf.

Habiburrahman, H. (2019). Islam dan Kapitalisme; Titik Temu dan Kritik Dalam Al-Qur'an. Indonesian Journal of Religion and Society, 2019, 01(01), 38-50. https://doi.org/10.36256/ijrs.v1i1.23

Hackman, J. R., \& Oldham, G. R. (1975). Work redesign. Canada : AddisonWesley Publishing Company, Inc

Liu, A. (2010). Measuring Spiritual Capital as a Latent Variable. The Research Methods Institute

McLennan, G. (2001). Sociological Cultural Studies: the Question of Explanation. Cultural Studies, 16(5), 631-649. https://doi.org/10.1080/0950238022000025200

Mudo, S. (2015, Agustus 26). Apa Itu Bisnis Startup dan Bagaimana Perkembanganya. Retrieved October 17, 2017, from techinasia: https://id.techinasia.com/talk/apa-itubisnis-startup-danbagaimana-perkembangannya

Palich, L.E., Hom, P.W., \& Griffeth, R.W. (1995), 'Managing in the International Context: Testing the Cultural Generality of Sources of Commitment to Multinational Enterprises,' Journal of Management, 21, 671-690.

Pudjiantoro, P, K, F \& Istadi, I (2019). Analisis Implementasi Pembinaan Karakter Karyawan Berbasis spiritual pada PT. Telkom Indonesia TBK. ISBN 978-602-52386-1-1

Rokeach. (1979). Beliefs Attitudes and Values. San Francisco: Josey-Bass.

Scott, R. (2004). Institutional Theory: Contributing to a Theoretical Research Program Institutional Theory : Contributing to a Theoretical Research Program Chapter prepared for Great Minds in Management: The Process of Theory. Great Minds in Management: The Process of Theory Development, (January 2005), 460-485. https://doi.org/10.1126/science. 1182238

Scott, W. R. (1995), Institutions and Organizations. Ideas, Interests and Identities. Management, vol. 17(2), 136-140. https://doi.org/10.3917/mana.172.0136.

Wahab, M. A. (2012). The Impact of Islamic Work Values on Employees 'Job Performance in Malaysia. PhD Thesis, Faculty of Business and Government, The University of Canberra, Australia, (February).

Zohar \& Marshall. 2004. Spiritual Capital. Bandung: Mizan. 